\title{
Autosomal dominant tubulointerstitial kidney disease
}

INSERM

\section{Source}

INSERM. (1999). Orphanet: an online rare disease and orphan drug data base. Autosomal dominant tubulointerstitial kidney disease. ORPHA:34149

A chronic tubulointerstitial nephropathy, which belongs, together with nephronophthisis $(\mathrm{NPH})$, to a heterogeneous group of inherited tubulo-interstitial nephritis, termed NPHMCKD complex. 